\title{
Vial Dosing Unit
}

National Cancer Institute

\section{Source}

National Cancer Institute. Vial Dosing Unit. NCI Thesaurus. Code C48551.

A dosing unit equal to the amount of active ingredient(s) contained in a sing le vial. 